\title{
Abdominal skin tensile strength in aesthetic and massive weight loss patients and its role in ventral hernia repair
}

\author{
Guilherme Barreiro ${ }^{1,25^{*}}$ (D), Vinícius S. de Lima ${ }^{2}$ and Leandro T. Cavazzola $a^{3,4}$
}

\begin{abstract}
Background: Clarifying the biomechanics of abdominal skin could lead to different uses for this tissue such as the ventral repair of hernias in patients with excess skin and incisional hernias. The objective of this study was to compare the maximum tensile strength of abdominal skin to commercial meshes and to verify whether or not it varies between aesthetic patients and massive weight-loss patients.
\end{abstract}

Methods: Experimental cross-sectional study. Skin samples sized $32 \times 20 \mathrm{~mm}$ were taken from 15 abdominoplasties and 10 panniculectomies. The skin specimens were analyzed in vertical and horizontal tensile strength tests. Results were compared between the two groups including their traction directions. Commercial meshes were also tested. The results were analyzed using the Generalized Estimating Equation.

Results: The maximum tensile strength supported vertically by abdominal dermis was $403.5 \pm 27.4 \mathrm{~N}$ in the abdominoplasty group and $425.9 \pm 33.9 \mathrm{~N}$ in the panniculectomy group. Horizontally, the values were $596.5 \pm 32.2 \mathrm{~N}$ and $612.5 \pm 43.9 \mathrm{~N}$ respectively. The strengths between traction directions were significantly different $(p<0.001)$. There were no differences between the groups with regard to the maximum tensile strength $(p=0.472)$. Tested commercial meshes had the following values: polypropylene $104.6 \mathrm{~N}$, low-weight polypropylene $54.4 \mathrm{~N}$, polytetrafluorethylene (PTFE) $82.2 \mathrm{~N}$, and hydrated porcine small-intestinal submucosa $60.0 \mathrm{~N}$.

Conclusion: In our study, the tensile strength of the tested human abdominal dermis samples, both aesthetic and post-bariatric, was superior to the commercial meshes. Therefore, in selected cases, abdominal dermis could be an alternative tool in abdominal reconstruction during panniculectomies with concomitant hernia repair.

Keywords: Abdominoplasty, Hernia repair, Plastic surgery, Bariatric surgery

\section{Background}

Incisional hernias are classified within the spectrum of ventral hernias, developing at sites of previous abdominal incisions. For this reason, their incidence is closely linked to the number of primary surgical interventions. With the recent increase in the number of laparotomies and laparoscopies, there has also been a rise in both the incidence of incisional hernias and the absolute costs generated with their treatment [1].

One of the main causative factors for incisional hernias is obesity. Data from the World Health

\footnotetext{
* Correspondence: plasticabarreiro@gmail.com

${ }^{1}$ Hospital de Clínicas de Porto Alegre, Universidade Federal do Rio Grande do Sul, Porto Alegre, Brazil

${ }^{2}$ Hospital Conceição, Porto Alegre, Brazil

Full list of author information is available at the end of the article
}

Organization (WHO) indicate that at least 2.8 million persons worldwide die annually due to being overweight [2]. The increase in the incidence and prevalence of this condition, as well as associated morbidity and mortality, have led to a $13 \%$ growth in the demand for bariatric surgeries between 2011 and 2013 in the U.S [3, 4]. One of the recent major complications related to this treatment is the development of incisional hernias, which can occur in up to $24 \%$ of cases in which laparotomic access is employed [5].

In the treatment of incisional hernias, hernioplasty with the use of meshes, both synthetic and biological, has established itself as the gold standard [6]. The use of prostheses, conceived by Billroth in the nineteenth century, aimed to reinforce the musculoaponeurotic 
component in contrast to the tendency of organs to insinuate themselves through the abdominal wall. The ideal mesh as proposed by Shankaran would be noncarcinogenic, capable of being sterilized, chemically inert, unlikely to produce a significant immune reaction, resistant to mechanical forces, infection, and visceral adherences, as well as amenable to large-scale production [7]. Unfortunately, that mesh does not yet exist, and currently used materials produce complications that cannot be ignored such as post-operative pain, infection, and recurrences [8].

The use of skin as a mesh in the correction of ventral hernias is a technique developed over 30 years ago; it is a popularly used treatment in European countries such as Germany, Italy, France, and Russia [9-11]. The technique's description, however, is hard to access because the lion's share of studies are described in the native language, which limits their impact in the global literature. Kama and collaborators demonstrated the proper performance of dermal autografts for correction of ventral hernias in an experimental study in an animal model [12]. In another relevant article, Korenkov and collaborators compared abdominal reconstructions in patients with simple and complex hernias with simple sutures to the use of autologous or alloplastic materials; they found no significant differences between the meshes and the autograft [13]. Existing comparative studies in the global literature provide evidence of autologous dermal mesh grafting as a tool that is, at a minimum, not inferior to commercial meshes in terms of clinical outcomes $[12,13]$. Since it is an autogenous material, it is also possible that the autograft would have lower rates of complications and lower costs.

The objective of the present study was to verify the maximum tensile strength of abdominal skin and compare it to the major commercially available meshes. Aesthetic and post-bariatric patients were assessed to allow comparison between the groups, and different directions of skin traction were analyzed. The working hypothesis of the research group was that the maximum tensile strength of the abdominal skin does not differ between aesthetic and post-bariatric patients, and that both are superior to commercial meshes.

\section{Methods}

This was an experimental cross-sectional study that evaluated as an outcome the maximum tensile strength of abdominal skin, in Newtons (N), of 25 patients who underwent abdominoplasties, 15 of which were aesthetic and 10 post-bariatric. Owing to the large influence of the measurement protocol in the parameter under evaluation, the choice was made not to use data from the literature to calculate the sample size, which was arbitrarily defined. The patients were enrolled sequentially at a Brazilian public hospital during the period from May to November 2015; patients who had previously undergone abdominoplasties, or presented with collagen diseases or any comorbidity that could significantly alter skin biomechanics were excluded.

The clinical histories of the patients were collected and included comorbidities, tobacco usage profile, and obstetric history. Anthropometric data were recorded using a graduated tape measure, with the goal of comparing the biotypes of the two groups. The abdominal circumference was defined as the smallest circumference measured between the end of the rib cage and the iliac crest. The xiphoid-genital distance was defined as the distance in a straight line between the xiphoid process and the pudendal cleft. The xiphoid-umbilical distance, like the umbilical-genital distance, considered skinfolds in such a way that, in some cases, their sum is a value greater than the xiphoid-genital distance. The angle of dorsiflexion of the surgical table was measured at the completion of the surgery using a digital goniometer (Everise Medical, Jiangsu, China). The dimensions of the resected specimen were also measured using graduated metric tape.

Of the dermal fat specimens resected during the surgery, four fragments measuring $32 \times 20 \mathrm{~mm}(\mathrm{~mm})$ were extracted, two for testing in the vertical direction relative to the main abdominal axis (one from the medial portion of the flap and others from the lateral portion), and two for testing in the horizontal direction, in the same position (Fig. 1) [14]. Samples of total skin were isolated from the subcutaneous tissue and submitted to a protocol defined by the research team. A system of clamps and screws was used for graduated distension of the skin with simultaneous measurement of the force produced by a dynamometer (Instrutherm ${ }^{\circ}$, DD-300 model) calibrated to the peak hold function (Fig. 2). The traction speed was defined as $5 \%$ extension of skin per second and kept constant until the rupture of the specimen.

For purposes of comparing human skin with commercial meshes, one sample of the same size from four different meshes was submitted to the identical protocol. Meshes made of high- and low-density polypropylene (Ethicon, Sommerville, NJ), polytetrafluoroethylene (W.L. Gore\&Associates, Flagstaff, AZ, USA) and hydrated porcine small intestinal submucosa (Cook Medical, Bloomington, IN, USA) were evaluated. The same traction speed was observed until total rupture of the sample being tested.

For the statistical analysis of the outcomes, the Generalized Estimating Equation (GEE) model was used, by which it was possible to identify interactions between the groups of aesthetic and post-bariatric patients and between different collection topographies. The 


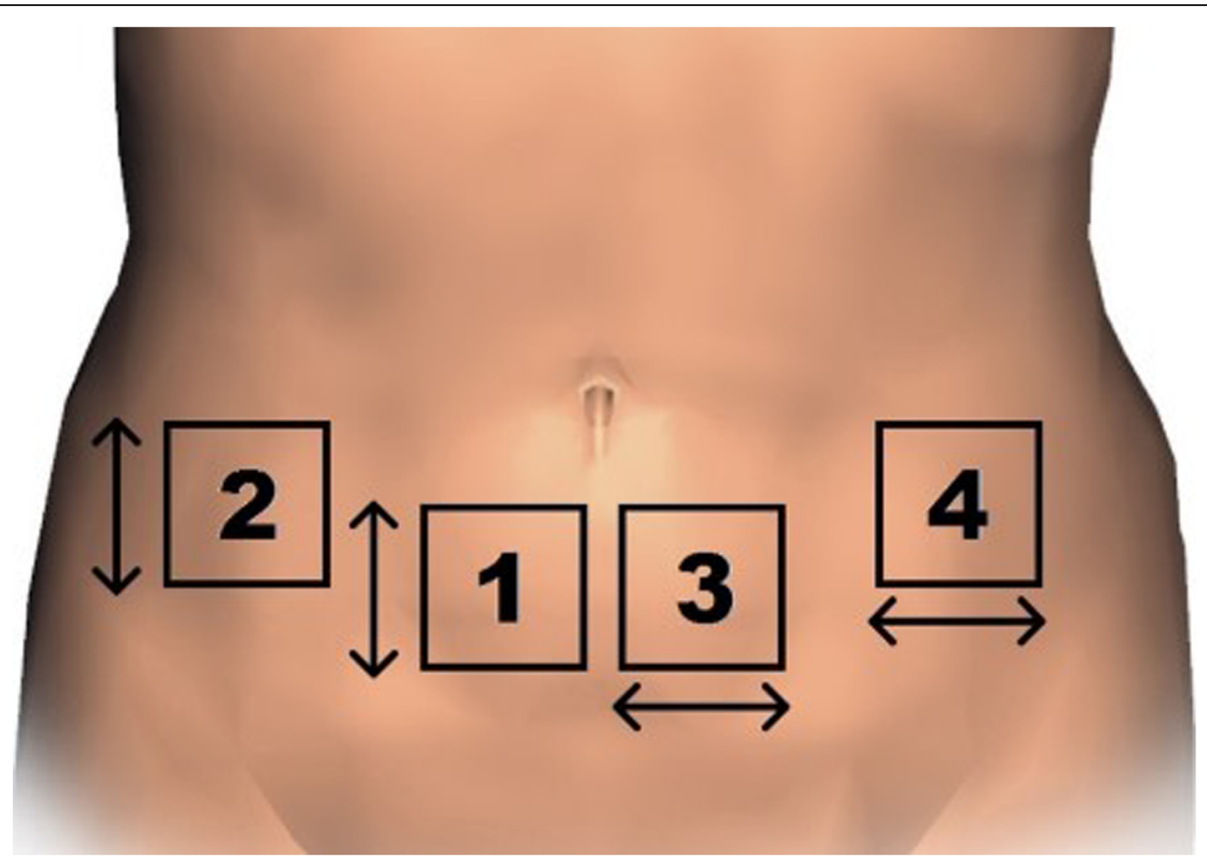

Fig. 1 Samples positions

calculation of the study power to detect non-inferiority was one-tailed and performed with the software WIN$\mathrm{PEPI}^{\circ}$. All the other tests were two-tailed, with $p<0.05$ defined as significant. The demographic and biometric characteristics were compared between the groups using the t-test, chi-squared distribution, and the MannWhitney $U$ test. The data are presented as mean \pm standard deviation (SD) or median (interquartile range). The project was approved by the Hospital de Clinicas de Porto Alegre Ethics Committee under CAAE 41787915.1.1001.5327, and all patients signed a consent form to participate in the research and to publish their cases. The Strengthening the Reporting of Observational Studies in Epidemiology (STROBE) checklist was used for the study report and its results [15].

\section{Results}

\section{Clinical features}

Fifteen aesthetic patients and 10 patients with massive weight loss were assessed. All of the analyzed patients were female. The mean age of the aesthetic patients was 37.2 years (range: 22 to 53 years) and that of the postbariatric patients was 45.9 years (range: 30 to 62 years), a significant difference $(p=0.037)$. The aesthetic patients suffered less frequently from comorbidities $(26.7 \%$ vs. $50 \%)$, but without statistical significance in the difference between the groups $(p=0.397)$. The number of pregnancies showed no differences $(p=0.232)$. The demographic data are presented in Table 1.

With respect to the anthropometric data, the abdominal circumference tended to be greater among the

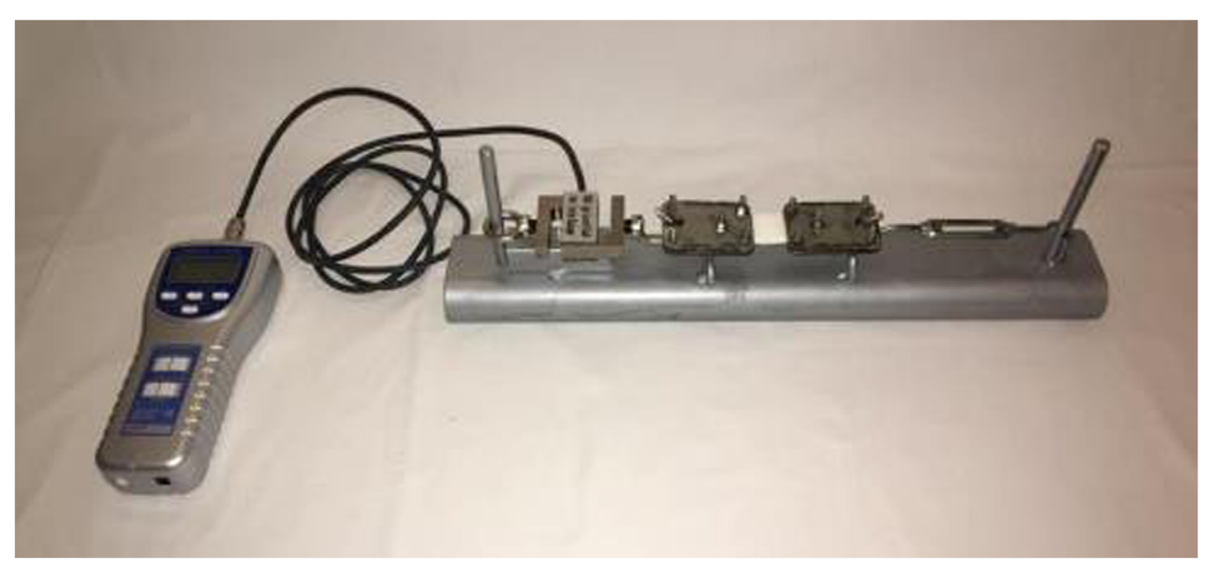

Fig. 2 System of clamps and screws used for graduated distension of the skin 
Table 1 Demographic Characteristics

\begin{tabular}{llll}
\hline & $\begin{array}{l}\text { Aesthetic } \\
\text { Patients }\end{array}$ & $\begin{array}{l}\text { Post-bariatric } \\
\text { Patients }\end{array}$ & $p$ \\
\hline No. & 15 & 10 & \\
Age (years) & & & \\
$\quad$ Mean & 37.2 & 45.9 & $0.037^{*}$ \\
$\quad$ Range & $22-53$ & $30-62$ & \\
Comorbidities (\%) & & & $0.397^{\#}$ \\
$\quad$ Yes & 26.7 & 50 & \\
$\quad$ No & 73.3 & 50 & $0.017^{\#}$ \\
Tobacco use (\%) & & & \\
$\quad$ Yes & 0 & 0 & $0.232^{\times}$ \\
$\quad$ No & 100 & 60 & $0.035^{*}$ \\
$\quad$ Ex-smoker & 0 & 40 & $3(1.5-5)$ \\
Pregnancies, median (IQ) & $2(1-3)$ & $29.5 \pm 4.7$ & \\
Mean BMl \pm SD & $25.7 \pm 1.3$ &
\end{tabular}

${ }^{\overline{ }} \mathrm{t}$-test; ${ }^{*}$ chi-squared; ${ }^{\times}$Mann-Whitney $U$ test

patients with massive weight loss $(83.8 \mathrm{~cm}$ vs. $90.7 \mathrm{~cm})$, but without statistical significance $(p=0.166)$. The body mass index (BMI) of the aesthetic patients was $25.7 \pm$ $1.3 \mathrm{~kg} / \mathrm{m}^{2}$, significantly less than that of the postbariatric patients, whose BMI was $29.5 \pm 4.7 \mathrm{~kg} / \mathrm{m}^{2}$ $(p=0.035)$. In addition, the only statistically significant difference was the distance between the navel and the genital region, which was $22 \mathrm{~cm}$ for the aesthetic patients and $25 \mathrm{~cm}$ for the other group $(p=0.002)$.

The dermal fat flaps resected from post-bariatric patients were significantly larger in their horizontal dimension, averaging $50.5 \mathrm{~cm}$, while the mean in aesthetic patients was $32.4 \mathrm{~cm}(p=0.002)$. The values from vertical measurement also tended to be greater, although without being mathematically significant $(p=0.095)$. The anthropometric and surgical data are shown in Table 2.

\section{Maximum tensile strength}

When the tensile strength of the skin was analyzed, the statistical model used did not detect a difference between the aesthetic and the post-bariatric patients $(p=0.472)$. Considering the sample size and the standard deviations of both groups, the study is able to say that there is no difference greater than $100 \mathrm{~N}$ in the postbariatric patients compared to the aesthetic patients, with a power of $85 \%$. The traction direction greatly influenced the values in both groups, leading to the conclusion that the tensile strength of the skin measured in the vertical direction is significantly different than that measured in the horizontal direction $(p<0.001)$.

Measurement 1 was $425.9 \mathrm{~N}$ in the post-bariatric patients and $403.5 \mathrm{~N}$ in the aesthetic patients. When the skin from the lateral portion of the abdomen was
Table 2 Biometric and Surgical Characteristics

\begin{tabular}{llll}
\hline & Aesthetic & Post-bariatric & $p$ \\
\hline No. & 15 & 10 & \\
$\begin{array}{l}\text { Abdominal circumference } \\
\text { mean } \pm \text { SD }(\mathrm{cm})\end{array}$ & $83.8 \pm 4.4$ & $90.7 \pm 14.0$ & $0.166^{*}$ \\
$\begin{array}{l}\text { Xiphoid-genital distance } \\
\text { mean } \pm \text { SD (cm) }\end{array}$ & $36.6 \pm 1.9$ & $37.6 \pm 4.3$ & $0.536^{*}$ \\
$\begin{array}{l}\text { Xiphoid-umbilical distance } \\
\text { mean } \pm \text { SD (cm) }\end{array}$ & $18.4 \pm 1.9$ & $19.7 \pm 3.4$ & $0.261^{*}$ \\
$\begin{array}{l}\text { Umbilical-genital distance } \\
\text { median (IQ) (cm) }\end{array}$ & $22(18-22)$ & $25(23.25-27.25)$ & $0.002^{*}$ \\
$\begin{array}{l}\text { Dorsiflexion angle } \\
\text { mean } \pm S D(\text { degrees })\end{array}$ & $154.0 \pm 7.4$ & $162.2 \pm 13.6$ & $0.106^{*}$ \\
$\begin{array}{l}\text { Craniocaudal size } \\
\text { of resection } \pm \text { SD }(\mathrm{cm})\end{array}$ & $19.0 \pm 2.7$ & $21.8 \pm 2.1$ & $0.095^{*}$ \\
$\begin{array}{l}\text { Latero-lateral size } \\
\text { of resection } \pm \text { SD }(\mathrm{cm})\end{array}$ & $32.4 \pm 3.6$ & $50.5 \pm 12.9$ & $0.002^{*}$ \\
\hline${ }^{*}$ ttest: ${ }^{*}$ Mann-Whitney $U$ test & & & \\
\hline
\end{tabular}

analyzed, reported by the research team as Measurement 2, there were similar values of $407.1 \mathrm{~N}$ and $369.7 \mathrm{~N}$, respectively. When the skin was pulled in the horizontal direction, on average (Measurement 3) the values were $612.5 \mathrm{~N}$ in the post-bariatric patients and $596.5 \mathrm{~N}$ in the aesthetic patients. In the lateral skin of the abdomen, designated Measurement 4, the latter had values of $561.3 \mathrm{~N}$, while results of the former were $591.3 \mathrm{~N}$ (Fig. 3).

When submitted to the same evaluation protocol, the commercial meshes yielded the following maximum tensile strength values: high-density polypropylene: $104.6 \mathrm{~N}$; low-density polypropylene: $54.4 \mathrm{~N}$; polytetrafluoroethylene: $82.2 \mathrm{~N}$; and hydrated porcine small intestinal submucosa: $60.6 \mathrm{~N}$. The values are reported in Table 3.

\section{Conclusion}

With regard to the characteristics of the groups, differences identified in age and BMI were statistically significant between the groups. However, despite the mathematical significance, these differences hardly play a clinically relevant role with respect to skin biomechanics since they have a reduced absolute value ( 8 years apart and 4 BMI points). The greatest distance from the navel to the genital region presented by the postbariatric patients was already expected, in view of the suprapubic abdominal crease characteristic of this group, popularly known as the panniculus or "abdominal apron" [16].

Concerning the maximum tensile strength, the statistical analysis of the biomechanical results of our study did not find a significant difference between the skin of post-bariatric and aesthetic patients (Additional file 1). The large standard deviation of the studied variable caused the sample size required for equivalence or non- 


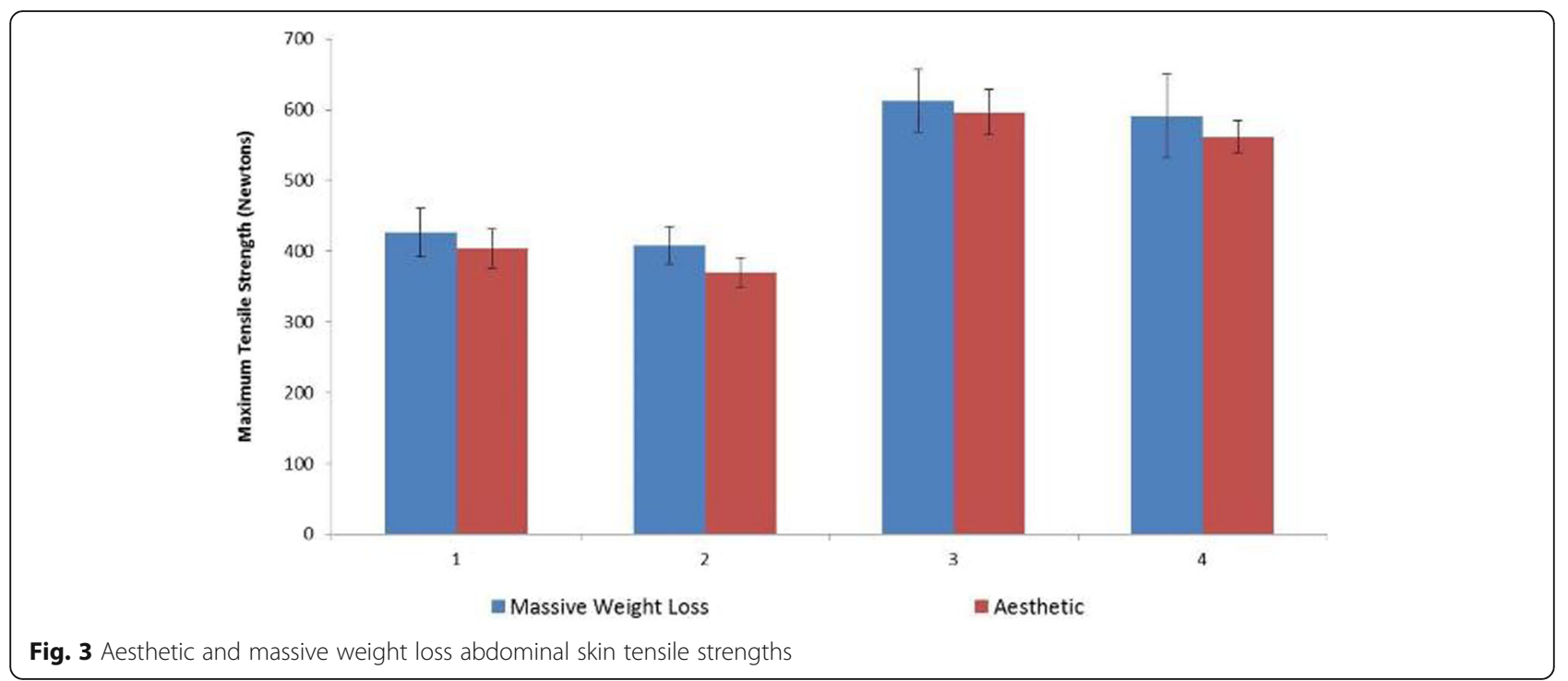

inferiority studies to be high. However, even with a sample of only 25 patients, statistically we can say-given a beta error of 0.15 -that the inferiority of the postbariatric patients compared to the aesthetic patients, if any, does not exceed $100 \mathrm{~N}$. In the context of the values presented, even if we assume that the abdominal skin of post-bariatric patients has a lower maximum tensile strength, its value would still be greater than that of the commercial meshes.

When the traction directions were compared, it was noted that the skin tissue had a greater resistance to being tested horizontally. This information can have a practical application in providing guidance for the positioning of grafts in corrective surgery for ventral hernias.

\section{Outlook for the future}

The study conducted by Mutlu and collaborators showed maximum tensile strength values of the abdominal skin similar to the values that we found [17]. In a series of 12 cases corrected with autograft, after an average follow-up period of 26 months, there were no recurrences diagnosed by the authors in clinical examination or in radiological study by MRI. However, only patients without a history of metabolic surgery were evaluated,

Table 3 Maximum Tensile Strength of Commercial Meshes Tested

\begin{tabular}{ll}
\hline Mesh & Strength \\
\hline High-density polypropylene & $104.6 \mathrm{~N}$ \\
Low-density polypropylene & $54.4 \mathrm{~N}$ \\
PTFE & $82.2 \mathrm{~N}$ \\
Hydrated porcine small-intestinal submucosa & $60.6 \mathrm{~N}$ \\
\hline
\end{tabular}

$N$ Newtons, PTFE polytetrafluorethylene just as a single traction direction was measured during the biomechanical tests.

Obesity is an independent risk factor for the development of ventral hernias [18]. Bariatric surgery, because it is performed in this population profile, ultimately results in a significant number of patients suffering from this pathology. Many of them will undergo reconstructive plastic surgery to improve their quality of life, during which there will be resection of brachial, crural, and abdominal dermal fat tissue, which today is discarded $[19,20]$.

The reuse of skin tissue as a substrate for abdominal reconstruction could reduce costs, minimize complications, and improve outcomes in the treatment of ventral hernias following bariatric surgeries. For this, however, it is essential to compare the biomechanical properties of the autograft with those of meshes currently in use. Our study used maximum tensile strength as the only outcome, which certainly does not exhaust the comparison of the two materials that is necessary [21]. Properties like elasticity and integration may differ significantly in the long term and were not the subject of the research study presented here.

The main limitation of our study is its design. It is known that, in some cases, experimental studies do not confirm their results in clinical trials and projects with greater methodological rigor. Another possible limitation was the non-de-epithelialization of the samples due to cost reduction issues. Although the epidermis does not significantly contribute to tensile strength, it is possible that its removal could cause a slight change in the abdominal skin tensile strength.

The results demonstrated in this research have opened new possibilities for future studies that approach dermal autograft as a tool for abdominal wall reconstruction in 
post-bariatric patients. This technique, if its benefits are confirmed, may make the plastic surgeon an important member of the multidisciplinary team assisting these individuals. In addition to its already recognized protagonism in the recovery of body contouring, rehabilitation of the musculoaponeurotic abdominal wall with the use of autologous material would open new horizons for global plastic surgery.

\section{Additional file}

Additional file 1: Aesthetic and post-bariatric data. Two sheets with clinical and numerical data collected from both groups of patients. The vertical and horizontal tensile strength tests are identified as MED1, MED2, MED3 and MED4. (XLSX 19 kb)

\section{Abbreviations}

BMI: Body mass index; CT: Computed tomography; GEE: Generalized Estimating Equation; mm: Millimeters; N: Newtons; SD: Standard deviation; STROBE: Strengthening the Reporting of Observational Studies in Epidemiology; WHO: World Health Organization

\section{Acknowledgements}

Hospital de Clinicas de Porto Alegre / FIPE for funding this publication.

\section{Authors' contributions}

GB: Study conception and design; acquisition of data; analysis and interpretation of data; drafting of manuscript; final approval of the version to be published. VSL: Study conception and design; critical revision; final approval of the version to be published. LTC: Study conception and design; analysis and interpretation of data; critical revision; final approval of the version to be published. All authors read and approved the final manuscript.

\section{Funding}

Research funded by Hospital de Clinicas de Porto Alegre / FIPE.

\section{Availability of data and materials}

The datasets generated and analysed during the current study are available from the corresponding author on reasonable request.

\section{Ethics approval and consent to participate}

The project was approved by the Hospital de Clinicas de Porto Alegre Ethics Committee under CAAE 41787915.1.1001.5327, and all patients signed a consent form to participate in the research and to publish their cases and the accompany image reported in this article.

\section{Consent for publication}

All patients including the index case signed a consent form for publication.

\section{Competing interests}

The authors declare that they have no competing interests.

\section{Author details}

${ }^{1}$ Hospital de Clínicas de Porto Alegre, Universidade Federal do Rio Grande do Sul, Porto Alegre, Brazil. ${ }^{2}$ Hospital Conceição, Porto Alegre, Brazil. ${ }^{3}$ Case Western Reserve University, Cleveland, OH, USA. ${ }^{4}$ Universidade Federal do Rio Grande do Sul, Porto Alegre, Brazil. ${ }^{5}$ Sinop/MT, Brazil.

Received: 6 December 2017 Accepted: 27 May 2019

Published online: 26 June 2019

\section{References}

1. Poulose BK, Shelton J, Phillips $\mathrm{S}$, et al. Epidemiology and cost of ventral hernia repair: Making the case for hernia research. Hernia. 2012;16(2):179-83.

2. World Health Organization. Global Health Observatory $(\mathrm{GHO})$ data. Available at: https://www.who.int/gho/ncd/risk factors/overweight/en/. Accessed 19 Aug 2016.
3. Flegal KM, Carroll MD, Ogden $\mathrm{CL}$, Johnson $\mathrm{CL}$. Prevalence and trends in obesity among US adults, 1999-2000. JAMA. 2002;288:1723.

4. American Society for Metabolic and Bariatric Surgery. Estimate of bariatric surgery numbers, 2011-2015. Available at https://asmbs.org/resources/ estimate-of-bariatric-surgery-numbers. Accessed 19 Aug 2016.

5. Nguyen NT, Ho HS, Palmer LS, Wolfe BM. A comparison study of laparoscopic versus open gastric bypass for morbid obesity. J Am Coll Surg. 2000;191:149.

6. Luijendijk RW, Hop WC, van den Tol MP, et al. A comparison of suture repair with mesh repair for incisional hernia. N Engl J Med. 2000;343:392.

7. Shankaran V, Weber DJ, Reed RL 2nd, Luchette FA. A review of available prosthetics for ventral hernia repair. Ann Surg. 2011;253(1):16-26.

8. Luijendijk RW, Hop WC, van den Tol MP, et al. A comparison of suture repair with mesh repair for incisional hernia. N Engl J Med. 2000;343(6):392-8.

9. Navarrini GC, Russo C, Armaroli R, Guerzoni AP. Skin grafts in the surgical treatment of incisional hernias. Ital J Surg Sci. 1987;17(1):49-53.

10. Nartsissov TV, Brezhnev VP. Autodermoplasty in postoperative hernias. Vestn Khir Im I Grek. 1991;146(5):40-2.

11. Korenkov M, Eypasch E, Paul A, Köhler L, Troidl H. Auto-dermal hernioplasty-a rare and unknown techniqueZentralbl Chir. 1997:122(10):871-8.

12. Kama NA, Coskun T, Yavuz H, Doganay M, Reis E, Akat AZ. Autologous skin graft, human dura mater and polypropylene mesh for the repair of ventral abdominal hernias: An experimental study. Eur J Surg. 1999;165:1080-5.

13. Korenkov M, Sauerland S, Arndt M, Bograd L, Neugebauer EAM, Troidl H. Randomized clinical trial of suture repair, polypropylene mesh or autodermal hernioplasty for incisional hernia. Br J Surg. 2002:89:50-6.

14. Modified from Blausen.com staff. "Blausen gallery 2014." Wikiversity Journal of Medicine. https://doi.org/10.15347/wjm/2014.010. ISSN 20018762.

15. von Elm E, Altman DG, Egger M, Pocock SJ, Gøtzsche PC, Vandenbroucke JP, STROBE Initiative. The Strengthening the Reporting of Observational Studies in Epidemiology (STROBE) Statement: Guidelines for Reporting Observational Studies. J Clin Epidemiol. 2008;61(4):344-9.

16. Manahan MA, Shermak MA. Massive panniculectomy after massive weight loss. Plast Reconstr Surg. 2006;117(7):2191-7 discussion 2198-2199.

17. Özkaya Mutlu Ö, Egemen O, Akan A, et al. The use of dermal automesh for incidental hernia repair in abdominoplasty: Clinical, biochemical, and radiological results. J Plast Surg Hand Surg. 2015:49(3):172-6.

18. Sauerland $S$, Korenkov M, Kleinen $T$, Arndt M, Paul A. Obesity is a risk factor for recurrence after incisional hernia repair. Hernia. 2004;8(1):42-6 Epub2003 Sep 6

19. van der Beek ES, Geenen R, de Heer FA, van der Molen AB, van Ramshorst B. Quality of life long-term after body contouring surgery following bariatric surgery: Sustained improvement after 7 years. Plast Reconstr Surg. 2012; 130(5):1133-9.

20. Bertheuil N, Thienot S, Chaput B, Varin A, Watier E. Quality-of-life assessment after medial thighplasty in patients following massive weight loss. Plast Reconstr Surg. 2015;135(1):67e-73e

21. Hussain SH, Limthongkul B, Humphreys TR. The biomechanical properties of the skin. Dermatol Surg. 2013;39(2):193-203.

\section{Publisher's Note}

Springer Nature remains neutral with regard to jurisdictional claims in published maps and institutional affiliations.

Ready to submit your research? Choose BMC and benefit from:

- fast, convenient online submission

- thorough peer review by experienced researchers in your field

- rapid publication on acceptance

- support for research data, including large and complex data types

- gold Open Access which fosters wider collaboration and increased citations

- maximum visibility for your research: over $100 \mathrm{M}$ website views per year

At $\mathrm{BMC}$, research is always in progress.

Learn more biomedcentral.com/submissions 